\title{
Substratos orgânicos no desenvolvimento de mudas de bacabi (Oenocarpus mapora
}

\author{
Karsten.) \\ Organic substrates in the development of bacabi (Oenocarpus mapora Karsten.) seedlings \\ Sustratos orgánicos en el desarrollo de plántulas de bacabi (Oenocarpus mapora Karsten.)
}

Recebido: 11/06/2021 | Revisado: 19/06/2021 | Aceito: 22/06/2021 | Publicado: 07/07/2021

Lucélia Rosa de Jesus Costa

ORCID: https://orcid.org/0000-0002-8291-6471 Universidade Federal Rural da Amazônia, Brasil E-mail: luceliarjagro@gmail.com

Maria do Socorro Padilha de Oliveira ORCID: https://orcid.org/0000-0002-4753-2018 Embrapa Amazônia Oriental, Brasil E-mail: socorro-padilha.oliveira@embrapa.br Camila Pinto Brandão ORCID: https://orcid.org/0000-0003-4658-1253 Universidade Federal Rural da Amazônia, Brasil E-mail: brandaopcamila@gmail.com

\begin{abstract}
Resumo
A produção de mudas de qualidade está relacionada ao nível de eficiência dos substratos, sendo essenciais em plantios de fruteiras perenes, como é o caso da palmeira bacabi (O. mapora). Entretanto, há carências de estudos que visem determinar o substrato ideal e sua eficiência na produção de mudas de bacabi. O objetivo deste trabalho foi avaliar substratos orgânicos no desenvolvimento de mudas dessa espécie. Foram utilizadas plântulas obtidas de sementes coletadas no banco de germoplasma de bacabas (Oenocarpus) da Embrapa Amazônia Oriental. As plântulas foram repicadas para sacos de polietileno preto, contendo três substratos: $100 \%$ de terriço, $75 \%$ de terriço+ $25 \%$ de esterco bovino e $60 \%$ de terriço+ $40 \%$ de cama de aviário. O delineamento utilizado foi o inteiramente ao acaso com três tratamentos e 20 repetições com parcela de uma muda. No período de doze meses foram avaliados, mensalmente: o número total de folhas (NTF), de folhas emitidas (NFE), o diâmetro do coleto (DC), taxa de sobrevivência (\%), matéria fresca da parte aérea (MFPA) e do sistema radicular (MFR) e seca da parte aérea (MSPA) e do sistema radicular (MSR). Os caracteres foram submetidos à análise de variância e ao teste Tukey ( $\mathrm{p} \leq 0,05)$. Os substratos diferiram para pelo menos um dos caracteres em seis avaliações. As maiores médias foram registradas nos substratos terriço e terriço+esterco bovino, principalmente nos caracteres NTF e DC. Para MFPA, MFR, MSPA e MSR o melhor substrato foi terriço+esterco. Portanto, o substrato terriço+esterco bovino promove o melhor desenvolvimento de mudas de bacabi.
\end{abstract}

Palavras-chave: Cama de aviário; Compostos orgânicos; Esterco bovino; Mudas de qualidade; Palmeira.

\begin{abstract}
The production of quality seedlings is related to the level of efficiency of the substrates, being essential in planting perennial fruit trees, as is the case of the bacabi palm (O. mapora). However, there is a lack of studies to determine the ideal substrate and its efficiency in bacabi seedling production. The objective of this work was to evaluate organic substrates in the development of seedlings of this specie. We used seedlings obtained from seeds collected at the Oenocarpus germplasm bank of Embrapa Eastern Amazon. The seedlings were transplanted to black bags containing three substrates: $100 \%$ soil, $75 \%$ soil $+25 \%$ bovine manure and $60 \%$ soil $+40 \%$ poultry litter. The design used was entirely random with three treatments and 20 repetitions with one seedling plot. During the twelve-month period, the following were evaluated monthly: total number of leaves (TNL), number of emitted leaves (NEL), diameter of the stalk (DS), survival rate (\%), fresh matter of the aerial part (FMAP) and root system (FMRS) and dry matter of the aerial part (DMAP) and root system (DMRS). The characters were submitted to variance analysis and Tukey test ( $p \leq$ 0.05). The substrates differed for at least one of the characters in six evaluations. The highest means were recorded on the substrates compost and compost+bovine manure, especially for the characters TNL and DS. For FMAP, FMRS, DMAP, and DMRS, the best substrate was terracing+stink. Therefore, the substrate soil+bovine manure promotes the best development of bacabi seedlings.
\end{abstract}

Keywords: Bovine manure; Organic composts; Palm; Poultry litter; Seedling quality. 


\begin{abstract}
Resumen
La producción de plántulas de calidad con el nivel de eficiencia de los sustratos es esencial en frutales perennes, como en la palma mapora (O. mapora). Sin embargo, hay pocos estudios para determinar el sustrato ideal y su eficacia en la producción de plántulas de plántulas mapora. El objetivo fue evaluar los sustratos orgánicos en el desarrollo de plántulas de esta especie. Se utilizaron plántulas, a partir de semillas recogidas del banco de germoplasma de Oenocarpus de Embrapa Amazonía Oriental. Las plántulas se transfirieron a bolsas negras conteniendo tres sustratos: $100 \%$ de tierra, $75 \%$ de tierra $+25 \%$ de estiércol bovino y $60 \%$ de tierra $+40 \%$ de cama de aves. El diseño fue totalmente aleatorio con tres tratamientos y 20 repeticiones con una parcela de siembra. Por doce meses, se evaluaron mensualmente el número total de hojas, hojas emitidas, diámetro del potro $(\mathrm{mm})$, tasa de supervivencia $(\%)$, materia fresca del brote y el sistema de raíces y materia seca de rodaje y el sistema de raíces. Los dados se sometieron a un análisis de la varianza y a la prueba de Tukey $(\mathrm{p} \leq 0,05)$. Los sustratos difirieron en al menos uno de los caracteres en seis evaluaciones. Las medias más altas se registraron en los sustratos tierra y tierra+estiércol bovino, para dos caracteres. En el caso de las materias frescas y secas, el mejor sustrato fue el de tierra+estiércol. Por lo tanto, el sustrato tierra+estiércol bovino favorece el mejor desarrollo de las plántulas de mapora.
\end{abstract}

Palabras clave: Abono orgánico; Calidad de las plántulas; Cama de aves; Estiércol bovino; Palmera.

\title{
1. Introdução
}

O Brasil se destaca como o terceiro país com maior diversidade de palmeiras nativas (Valois, 2014), dentre elas têmse a bacabi (Oenocarpus mapora Karsten), palmeira perene nativa da Amazônia, cujos frutos quando processados, produzem refresco de excelente qualidade denominado de "bacaba" concorrente direto do açaí. Trata-se de uma espécie de bacaba com precocidade de produção, estipe em touceira e frutos de excelente qualidade nutricional e de grande potencialidade para a agroindústria de polpa e palmito (Oliveira \& Moura, 2010). Apesar de suas potencialidades poucos estudos têm sido realizados para subsidiar cultivos racionais dessa frutífera, haja vista que se trata de uma espécie ainda não domesticada (Clement, 2001), com a carência de conhecimentos básicos indo desde a produção de mudas de qualidade até informações sobre o manejo de plantios de larga escala.

A produção de mudas de qualidade garante o sucesso no estabelecimento de pomares produtivos de qualquer espécie frutífera, ou seja, mudas sadias e vigorosas apresentam grande importância (Cordeiro et al., 2020). Na formação desse tipo de mudas, o nível de eficiência dos substratos e dos recipientes, são considerados essenciais para o êxito de plantios de fruteiras perenes (Muller et al., 2004; Caldeira et al., 2008), principalmente o substrato naquelas propagadas por sementes, por ser responsável pela retenção de água e pela nutrição da planta (Alves et al., 2021). O substrato também auxilia no desenvolvimento radicular, respondendo pela boa formação das mudas, tornando-as viáveis para serem conduzidas ao campo (Marques et al., 2017). Ressalta-se que apesar da bacabi ser predominantemente multicaule, possui como principal forma de propagação a sexuada, cujas sementes apresentam alta taxa de germinação, se forem semeadas no mesmo dia do beneficiamento dos frutos (Oliveira \& Oliveira, 2015). Dessa forma, se faz necessário identificar os substratos que promovam as melhores condições para o desenvolvimento de mudas de qualidade para essa palmeira.

Há vários substratos disponíveis sendo testados na produção de mudas de espécies frutíferas (Barros et al., 2020; Cordeiro et al., 2020; Oliveira et al., 2020), inclusive de palmeiras (Fior et al., 2014; Pimentel et al., 2016) indo dos orgânicos aos inorgânicos, podendo estar associados ou não, além de serem constituídos em diferentes proporções repercutindo na qualidade das mudas. Substratos orgânicos, de origem vegetal e animal, são fundamentais para a manutenção das características físicas, químicas e biológicas do solo (Menezes Júnior \& Fernandes, 1999). Esses substratos quando aplicados ao solo, aumentam a aeração e a retenção de água, sendo também as principais fontes de macro e micronutrientes para plantas (Nicolau Sobrinho, 2007). Ressalta-se que os substratos formulados com esterco de animais são responsáveis pela formação de mudas com maior número de folhas, devido ao incremento da matéria orgânica (Cavalcante et al., 2016; Pinheiro et al., 2018).

Na produção de mudas de palmeiras é comum o uso de substratos orgânicos, especialmente esterco bovino e cama de aviário, os quais podem ser acrescentados em diferentes proporções ao solo. Em mudas de pupunheira (Bactris gasipaes Kunth) o melhor desenvolvimento ocorre em solo homogeneizado acrescido de esterco bovino (Silva et al., 2009; Martins 
Filho et al., 2007). Para a palmeira ráfia (Rhaphis excelsa) substratos contendo esterco bovino e cascas de arroz carbonizadas produzem mudas de qualidade (Luz et al., 2007). Em mudas de bocaiúva (Acrocomia aculeata) substratos contendo esterco bovino também são os mais indicados (Martins, 2011). Outros estudos abordam o uso de substratos em mudas de outras palmeiras (Brahm et at, 2013; Garcia et al, 2012; Luz et at, 2013; Wanderley et al, 2012). Mas, não há relatos sobre substratos que possam contribuir com a produção de mudas da palmeira em foco. Com isso, o objetivo deste trabalho foi analisar a eficiência de substratos orgânicos na contribuição para o desenvolvimento de mudas de bacabi.

\section{Metodologia}

\subsection{Localização e condições experimentais}

O experimento foi conduzido no viveiro de produção de mudas de palmeiras da Embrapa Amazônia Oriental,

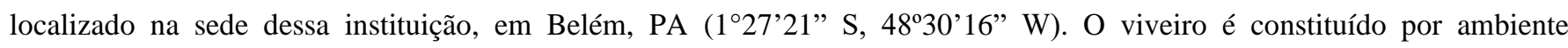
protegido, sendo de estrutura em aço galvanizado, possuindo $6 \mathrm{~m}$ de largura, $10 \mathrm{~m}$ de comprimento e $3 \mathrm{~m}$ de altura, revestido de tela sombrite preta com $50 \%$ de interceptação de luz nas laterais e cobertura, com uma camada de $10 \mathrm{~cm}$ de seixo no solo. $\mathrm{O}$ clima local é Afi classificado por Köppen, com médias de $2.740 \mathrm{~mm}$ de precipitação e $26^{\circ} \mathrm{C}$ de temperatura e $90 \%$ de umidade relativa do ar (INMET, 2019).

\subsection{Condução do experimento}

As plântulas de bacabi foram obtidas por sementes lavadas e semeadas em sementeiras, logo após o beneficiamento de frutos maduros, retirados de um cacho colhido no Banco Ativo de Germoplasma de Bacabas (Oenocarpus) dessa instituição.

Foram utilizadas 60 plântulas no estágio de palito (primórdio caulinar constituído por bainhas que envolvem a primeira folha) com $3 \mathrm{~cm}$ de altura (Figura 1A). Como recipientes foram usados sacos de polietileno preto, sanfonados e perfurados, nas dimensões de $17 \mathrm{~cm}$ x $27 \mathrm{~cm}$ x 0,2 mm, com capacidade para 2 litros preenchidos com três tipos de substratos. Cada plântula foi colocada no centro do recipiente e a $2 \mathrm{~cm}$ de profundidade de cada substrato.

Os substratos testados foram:

1) $100 \%$ de terriço, ou seja, solo da camada superficial, até $20 \mathrm{~cm}$ de profundidade, coletado em área de capoeira;

2) $75 \%$ de terriço $+25 \%$ de esterco bovino curtido;

3) $60 \%$ de terriço $+40 \%$ de cama de aviário curtida.

Cada substrato foi analisado no laboratório de solos da instituição com as composições químicas descritas na Tabela 1 , sendo que a granulometria do substrato terriço foi de textura média.

Tabela 1. Teor de matéria orgânica (M.O), nitrogênio $(\mathrm{N})$, acidez ativa $(\mathrm{pH})$, fósforo $(\mathrm{P})$, potássio $(\mathrm{K})$, sódio $(\mathrm{Na})$, cálcio $(\mathrm{Ca})$, cálcio + magnésio $(\mathrm{Ca}+\mathrm{Al})$ alumínio trocável $(\mathrm{Al})$ e acidez potencial $(\mathrm{H}+\mathrm{Al})$ em cada substrato utilizado neste estudo.

\begin{tabular}{lcccccccccc}
\hline Composição & $\mathrm{M} . \mathrm{O}$ & $\mathrm{N}$ & $\mathrm{pH}$ & $\mathrm{P}$ & $\mathrm{K}$ & $\mathrm{Na}$ & $\mathrm{Ca}$ & $\mathrm{Ca}+\mathrm{Mg}$ & $\mathrm{Al}$ & $\mathrm{H}+\mathrm{Al}$ \\
\hline & $\mathrm{g} \mathrm{kg}^{-1}$ & $\%$ & $\mathrm{H}_{2} \mathrm{O}$ & \multicolumn{5}{c}{$\mathrm{mg} \mathrm{dm}^{-3}$} & \multicolumn{5}{c}{$\mathrm{cmol}_{\mathrm{c}} \mathrm{dm}^{-3}$} \\
Terriço & 16,25 & 0,05 & 5,5 & 276 & 22 & 3 & 5,2 & 4,8 & 0,1 & 4,95 \\
Esterco de gado & - & 3,20 & - & 25,13 & 3,55 & 0,75 & - & - & - & - \\
Cama de aviário & - & 5,25 & - & 11,37 & 5,37 & 0,41 & - & - & - & - \\
\hline
\end{tabular}

Fonte: Autores. 


\subsection{Desenho experimental e manejo das mudas}

O delineamento experimental foi o inteiramente casualizado (DIC), com três tratamentos (substratos), 20 repetições e parcela constituída por uma muda. As mudas foram mantidas no viveiro, recebendo $50 \%$ de luminosidade, com irrigação diária, além de controle de plantas espontâneas (monda) quinzenal.

\subsection{Avaliação das variáveis respostas}

As mudas foram avaliadas, mensalmente, durante doze meses para as seguintes características: número total de folhas (NTF), obtido pela contagem de todas as folhas (Figura 1B); número de folhas emitidas (NFE), pela contagem da folha mais nova expandida, marcada com fita plástica de diferentes cores para facilitar sua identificação (Figura 1C); diâmetro do coleto (DC), retirado da base da muda com o auxílio de paquímetro digital expresso em milímetros (Figura 1D). Na última avaliação, no $12^{\circ}$ mês (Figura 1E) obteve-se também a taxa de sobrevivência das mudas. Em seguida, as plantas foram seccionadas a altura do colo, para as pesagens em balança de precisão das matérias frescas e secas parte aérea (MFPA e MSPA) e do sistema radicular (MFR e MSR) (Figura 1F). As matérias secas foram obtidas em estufa de circulação forçada de ar a $65^{\circ} \mathrm{C}$ por 72 horas.

Figura 1. Plântulas no estágio de palito (A) e variáveis avaliadas nas mudas de bacabi (O. mapora): número total de folhas (B), número de folhas emitidas (C), diâmetro do coleto (D), taxa de sobrevivência ao $12^{\circ}$ mês (E) e, parte aérea e sistema radicular $(\mathrm{F})$.

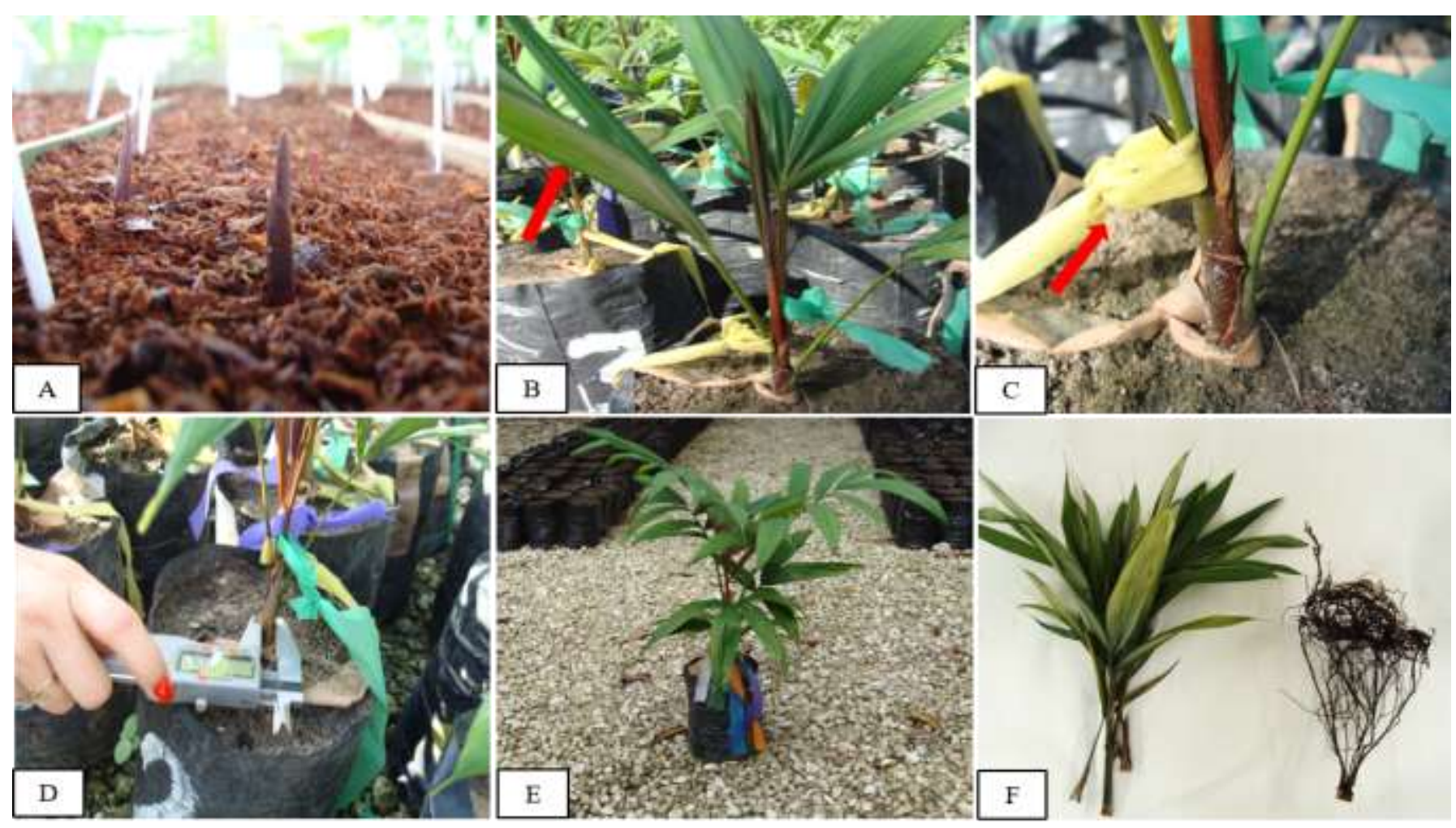

Fonte: Autores.

\subsection{Análise estatística}

Os dados foram submetidos à análise de variância (Teste F) no software GENES (Cruz, 2001) com base no delineamento adotado (DIC). As médias que diferiram entre si foram comparadas pelo teste de Tukey $5 \%$ de probabilidade. 


\section{Resultados e Discussão}

Foram detectadas diferenças significativas entre os substratos testados, para, pelo menos, uma das características, em seis das doze avaliações (Tabela 2). No primeiro e quarto mês os tratamentos diferiram entre si para o diâmetro do coleto (DC). No segundo mês foi detectada diferença significativa para número total de folhas (NTF) e de folhas emitidas (NFE). No terceiro e nono mês a diferença ocorreu para número de folha emitida (NFE). Enquanto, na última avaliação, os tratamentos diferiram para o número total de folhas, diâmetro do coleto, taxa de sobrevivência e para pesos de matéria fresca da parte aérea (MFPA), do sistema radicular (MFR) e de matéria seca da parte aérea (MSPA) e do sistema radicular (MSR). Os coeficientes de variação foram bastante variáveis ao longo das avaliações, mas dentro do esperado para experimentos dessa natureza, com o diâmetro do coleto e o número total de folhas exibindo as menores variações.

Tabela 2. Quadrados médios para número total de folhas (NTF), de folhas /emitidas (NFE), diâmetro do coleto (DC), matéria fresca da parte aérea (MFPA) e da raiz (MFR) e matéria seca da parte aérea (MSPA) e da raiz (MSR) em mudas de O. mapora, submetidas a diferentes substratos, obtidos em seis avaliações. Belém - PA.

\begin{tabular}{|c|c|c|c|c|c|c|}
\hline \multirow[t]{2}{*}{ Caracteres } & \multicolumn{6}{|c|}{ Avaliações } \\
\hline & $1^{\circ}$ mês & $2^{\circ}$ mês & $3^{\circ}$ mês & $4^{\circ}$ mês & $9^{\circ}$ mês & $12^{\circ}$ mês \\
\hline NTF $\left(n^{0}\right)$ & . & $0,6842^{*}$ & $0,1579^{\mathrm{ns}}$ & $0,7544^{\mathrm{ns}}$ & $0,4912^{\text {ns }}$ & $2,1228^{*}$ \\
\hline $\mathrm{CV}(\%)$ & . & 32,0 & 27,99 & 25,6 & 15,24 & 9,86 \\
\hline Média & . & 1,2 & 1,7 & 2,2 & 5,0 & 6,4 \\
\hline NFE $\left(n^{0}\right)$ & . & $0,6842^{*}$ & $1,3158^{* *}$ & $0,0175^{\mathrm{ns}}$ & $0,6842^{*}$ & $0,1579^{\mathrm{ns}}$ \\
\hline $\mathrm{CV}(\%)$ & . & 184,2 & 97,76 & 104,42 & 127,39 & 119,09 \\
\hline Média & . & 0,2 & 0,5 & 0,5 & 0,4 & 0,4 \\
\hline DC (mm) & $1,7524^{*}$ & $1,0674^{\mathrm{ns}}$ & $1,4341^{\mathrm{ns}}$ & $5,2374^{*}$ & $15,0458^{\mathrm{ns}}$ & $39,8005^{*}$ \\
\hline $\mathrm{CV}(\%)$ & 16,91 & 21,15 & 21,1 & 19,1 & 2194 & 17,17 \\
\hline Média & 3,7 & 4,3 & 5,1 & 6,4 & 13,9 & 18,4 \\
\hline$\overline{M F P A}(\mathrm{~g})$ & . & . & . & . & . & $5,4778^{*}$ \\
\hline $\mathrm{CV}(\%)$ & . & . & . & . & . & 34,56 \\
\hline Média & . & . & . & . & . & 53,6 \\
\hline MFR (g) & . & . & . & . & . & $1,0184^{*}$ \\
\hline $\mathrm{CV}(\%)$ & . & . & . & . & . & 43,43 \\
\hline Média & . & . & . & . & . & 32,2 \\
\hline MFPA (g) & . & . & . & . & . & $895,2416^{*}$ \\
\hline $\mathrm{CV}(\%)$ & . & . & . & . & . & 34,75 \\
\hline Média & . & . & . & . & . & 22 \\
\hline MFR (g) & . & . & . & . & . & $91,3539^{*}$ \\
\hline $\mathrm{CV}(\%)$ & . & . & . & . & . & 38,17 \\
\hline Média & . & . & . & . & . & 11,4 \\
\hline
\end{tabular}


Aos doze meses as mudas de bacabi apresentaram, em média, 6,4 folhas e 18,4 mm de diâmetro do coleto, com incremento de aproximadamente 6,0 folhas e $14,8 \mathrm{~mm}$ de diâmetro ao longo da avaliação, sugerindo que a composição dos substratos exerceu influência positiva no desenvolvimento vegetativo das mudas. O número de folhas se aproximou proporcionalmente ao considerado pela Comissão Estadual de Sementes e Mudas do Pará (CESM, 1997) para a produção de mudas de açaizeiro (Euterpe oleracea) de qualidade.

Na Tabela 3 constam as comparações das médias entre os substratos para os caracteres que apresentaram diferenças nas seis avaliações. Percebe-se que no primeiro e segundo mês o melhor substrato foi o terriço, seguido pelo terriço + cama de aviário para a característica diâmetro do caule e também para o número total de folhas e de folhas emitidas. Nos demais meses o destaque ficou com o substrato terriço + esterco bovino, seguido pelo terriço, inclusive na última avaliação onde se avaliou também a taxa de sobrevivência, os pesos da matéria fresca e seca da parte aérea e da raiz (Tabela 4), sugerindo que esses substratos promovam maiores ganhos de massa nas mudas de bacabi e, por conseguinte, influenciando na qualidade das mesmas. Barros et al. (2020) ao avaliarem o efeito de diferentes substratos orgânicos em mudas de mamoeiro constataram que o esterco de curral proporcionou o melhor desenvolvimento das mudas. Outros autores também enfatizam a importância de esterco de animais na formulação de substratos para a produção de mudas por promoverem o maior número de folhas e associam esse efeito ao incremento de matéria orgânica nesses substratos (Cavalcante et al., 2016; Pinheiro et al., 2018; Guse et al., 2021). Para Marques et al. (2017) o substrato além de ser essencial, auxilia no desenvolvimento radicular, sendo responsável pela boa formação das mudas, tornando-as viáveis para o plantio. 
Tabela 3. Médias para número total de folhas (NTF), de folhas emitidas (NFE) e diâmetro do coleto (DC) em mudas de $O$. mapora, submetidas a diferentes substratos, em seis avaliações, Belém - PA.

\begin{tabular}{|c|c|c|c|}
\hline Substratos & NTF $\left(n^{0}\right)$ & NFE $\left(n^{0}\right)$ & DC (mm) \\
\hline & \multicolumn{3}{|c|}{$1^{o} \mathrm{mês}$} \\
\hline Terriço $(100 \%)$ & - & - & $3,93 \mathrm{a}$ \\
\hline Terriço $(75 \%)+$ Esterco bovino (25\%) & - & - & $3,35 \mathrm{~b}$ \\
\hline \multirow{2}{*}{ Terriço $(60 \%)$ + Cama de aviário (40\%) } & - & - & $3,8 \mathrm{ab}$ \\
\hline & \multicolumn{3}{|c|}{$2^{o} m \hat{e} s$} \\
\hline Terriço $(100 \%)$ & $1,42 \mathrm{a}$ & $0,42 \mathrm{a}$ & $4,18 \mathrm{a}$ \\
\hline Terriço $(75 \%)+$ Esterco bovino $(25 \%)$ & $1,05 b$ & $0,05 \mathrm{~b}$ & $4,20 \mathrm{a}$ \\
\hline \multirow[t]{2}{*}{ Terriço $(60 \%)+$ Cama de aviário $(40 \%)$} & $1,16 \mathrm{ab}$ & $0,16 \mathrm{ab}$ & $4,60 \mathrm{a}$ \\
\hline & \multicolumn{3}{|c|}{$3^{o} m \hat{e} s$} \\
\hline Terriço $(100 \%)$ & $1,63 \mathrm{a}$ & $0,21 \mathrm{~b}$ & $5,11 \mathrm{a}$ \\
\hline Terriço $(75 \%)+$ Esterco bovino $(25 \%)$ & $1,79 \mathrm{a}$ & $0,73 \mathrm{a}$ & $4,83 \mathrm{a}$ \\
\hline \multirow[t]{2}{*}{ Terriço $(60 \%)$ + Cama de aviário (40\%) } & $1,63 \mathrm{a}$ & $0,47 \mathrm{ab}$ & $5,38 \mathrm{a}$ \\
\hline & \multicolumn{3}{|c|}{$4^{o} m e ̂ s$} \\
\hline Terriço $(100 \%)$ & $1,95 \mathrm{a}$ & $0,47 \mathrm{a}$ & $5,86 \mathrm{~b}$ \\
\hline Terriço $(75 \%)+$ Esterco bovino $(25 \%)$ & $2,32 \mathrm{a}$ & $0,53 \mathrm{a}$ & $6,91 \mathrm{a}$ \\
\hline \multirow[t]{2}{*}{ Terriço $(60 \%)+$ Cama de aviário $(40 \%)$} & $2,63 \mathrm{a}$ & $0,47 \mathrm{a}$ & $6,29 a b$ \\
\hline & \multicolumn{3}{|c|}{$9^{o} m \hat{e} s$} \\
\hline Terriço $(100 \%)$ & $5,10 \mathrm{a}$ & $0,57 \mathrm{a}$ & $13,51 \mathrm{a}$ \\
\hline Terriço $(75 \%)+$ Esterco bovino $(25 \%)$ & $5,00 \mathrm{a}$ & $0,21 \mathrm{~b}$ & $14,90 \mathrm{a}$ \\
\hline \multirow[t]{2}{*}{ Terriço $(60 \%)$ + Cama de aviário (40\%) } & $4,78 \mathrm{a}$ & $0,31 \mathrm{ab}$ & $13,24 \mathrm{a}$ \\
\hline & \multicolumn{3}{|c|}{$12^{\circ} m \hat{e} s$} \\
\hline Terriço $(100 \%)$ & $6,63 \mathrm{a}$ & $0,47 \mathrm{a}$ & $18,84 \mathrm{ab}$ \\
\hline Terriço $(75 \%)+$ Esterco bovino $(25 \%)$ & $6,63 \mathrm{a}$ & $0,47 \mathrm{a}$ & 19,65 a \\
\hline Terriço $(60 \%)$ + Cama de aviário $(40 \%)$ & $6,05 \mathrm{~b}$ & $0,35 \mathrm{a}$ & $16,84 \mathrm{~b}$ \\
\hline
\end{tabular}

Médias seguidas de mesma letra na coluna não diferem entre si, pelo teste de Tukey a 5\% de probabilidade. Fonte: Autores.

O diâmetro do coleto e o número total de folhas foram às características que mais evidenciaram diferenças entre os substratos. Esses caracteres também foram mencionados como importantes na avaliação de mudas de outras palmeiras (Brahm et al., 2013; Garcia et al., 2012; Luz et al., 2013; Martins Filho et al., 2007; Wanderley et al., 2012; Fior et al., 2014; Pimentel et al., 2016). Para Kratz (2011) esses dois caracteres exercem influência positiva sobre a taxa de sobrevivência e crescimento inicial das plantas no plantio, sugerindo que quanto maior o diâmetro melhor será o equilíbrio entre a raiz e a parte aérea, tornando as mudas mais rústicas. Um bom desenvolvimento do coleto, durante a formação de mudas, reflete aspecto de mudas vigorosas, uma vez que tamanho do diâmetro está relacionado à capacidade de transporte de fotoassimilados da planta (Araújo et al., 2020). Essas informações são relevantes, pois assim como Pereira (2005) acredita-se que o sucesso no plantio de plantas perenes seja dependente do uso de mudas vigorosas e sadias.

Substratos acrescidos de estercos de bovino e de búfalo formaram mudas com maiores números de folhas e diâmetro do coleto em Bactris gasipaes (Martins Filho et al., 2007; Garcia et al., (2012) e de Euterpe edulis (Luz et al., 2013), demonstrando a eficiência de fontes orgânicas na formação de mudas, com destaque para o esterco bovino, corroborando com 
os resultados aqui obtidos. Porém, Brahm et al. (2013) ao avaliarem as mesmas características em mudas de E. edulis e Rystonea regia, não encontraram diferenças entre os substratos para esses caracteres, mas as maiores médias ocorreram em substrato com $100 \%$ de solo do mato.

No caso do número de folhas emitidas os resultados estão em concordância com os obtidos por Martins et al. (2007) e Wanderley et al. (2012) que ao avaliarem diferentes substratos em mudas de B. gasipaes e Phoenix roebelenii constataram a maior emissão de folhas em substratos acrescidos de fontes orgânicas, especialmente esterco bovino. Possivelmente, isso esteja relacionado ao maior teor de $\mathrm{N}$ (elemento essencial às plantas) que constitui a molécula de clorofila, aminoácidos, proteínas e ácidos nucléicos, componentes que fazem parte do processo fotossintético das plantas, bem como produção de fotoassimilados (Taiz et al., 2017).

Na última avaliação (aos doze meses) o substrato terriço + esterco bovino se destacou na comparação entre as médias das características de matéria fresca (MFPA e MFR), de matéria seca (MSPA e MSR), seguido pelo substrato terriço (Tabela 4) enfatizando a relevância do acréscimo desse adubo orgânico na composição do substrato para a produção de mudas de bacabi. Nessa avaliação as mudas dessa palmeira apresentaram altas taxas de sobrevivência, com os substratos terriço e terriço + esterco bovino exibindo 100\%. Brahum et al. (2013) e Fior et al. (2014) também obtiveram elevada taxa sobrevivência em mudas de E. edulis (84,4\%), Rystonea regia $(99,4 \%)$ e Butia odorata (100\%), mas não detectaram diferenças entre os substratos orgânicos para essa característica. Em relação às matérias fresca e seca da parte aérea e da raiz, Martins Filho et al. (2007) também detectaram maiores ganhos de massa seca da parte aérea no substrato acrescido de esterco bovino. Porém, Luz et al. (2013) ao avaliarem as mesmas características em mudas de Euterpe edulis observaram maiores ganhos de massa nos substratos Plantmax ${ }^{\circledR}$ e terra + cama de frango. Pode-se considerar que alta quantidade de matéria seca, na parte aérea e na raiz indica muda de excelente qualidade, pois reflete no crescimento em função da quantidade de nutrientes absorvidos, estimulando a sobrevivência e o crescimento inicial das mudas em campo (Gomes \& Paiva, 2006; Franco et al., 2007). Além disso, está relacionada com a qualidade e o número de folhas, fonte de nutrientes e fotoassimilados necessários para a adaptação da muda pós plantio, servindo como suprimento de água e nutrientes para as raízes (Bellote \& Silva, 2000).

Tabela 4. Médias para matéria fresca da parte aérea (MFPA) e da raiz (MFR) e de matéria seca da parte aérea (MSPA) e da raiz (MSR) e taxa de sobrevivência, obtidas aos doze meses, em mudas de bacabi (O. mapora) submetidas a diferentes substratos, Belém - PA.

\begin{tabular}{cccccc}
\hline Substratos & MFPA & MFR & MSPA & MSR & Sobrevivência \\
& $(\mathbf{g})$ & $(\mathbf{g})$ & $(\mathbf{g})$ & $(\mathbf{g})$ & $(\boldsymbol{\%})$ \\
\hline Terriço $(100 \%)$ & $61,3 \mathrm{a}$ & $34,66 \mathrm{ab}$ & $26,65 \mathrm{a}$ & $12,16 \mathrm{ab}$ & $100,0 \mathrm{a}$ \\
Terriço $(75 \%)+$ Esterco bovino $(25 \%)$ & $65,3 \mathrm{a}$ & $37,95 \mathrm{a}$ & $25,24 \mathrm{a}$ & $13,15 \mathrm{a}$ & $100,0 \mathrm{a}$ \\
Terriço $(60 \%)$ + Cama de aviário (40\%) & $34,12 \mathrm{~b}$ & $23,95 \mathrm{~b}$ & $14,12 \mathrm{~b}$ & $8,95 \mathrm{~b}$ & $95,0 \mathrm{~b}$ \\
\hline
\end{tabular}

Médias seguidas de mesma letra na coluna não diferem entre si, pelo teste de Tukey a 5\% de probabilidade. Fonte: Autores.

Durante o período do estudo foram observados sintomas de ataque de insetos e de fungos em algumas mudas de bacabi desenvolvidas nos substratos contendo $100 \%$ de terriço e com $60 \%$ de terriço+ $40 \%$ de cama de aviário. No substrato constituído apenas por terriço esses sintomas não ocasionaram a morte das plantas. Os sintomas dos insetos foram similares aos provocados pela lagarta-verde do coqueiro (Synale hylapses) em mudas de E. oleracea, que se alimentam do limbo foliar 
tornando-o esgaçado, seco e amarronzado. O fungo foi registrado como Pestalotiopis $s p$ e causa pequenas manchas em folhas de palmáceas, que coalescem o tecido, e progridem provocando a seca das folhas comprometendo toda a muda, principalmente as mais jovens (Russomano et al., 2007). Fior et al. (2014) não observaram sintomas de pragas ou doenças em mudas de $B$. odorata conduzidas em substrato formado apenas por casca de arroz carbonizada.

De um modo geral, na composição do substrato a parte orgânica é responsável pela retenção de umidade e no fornecimento de nutrientes e apresentam os melhores resultados na produção de mudas (Araújo \& Paiva Sobrinho, 2011; Cordeiro et al., 2020; Oliveira et al. 2020), sendo o esterco bovino a principal fonte orgânica utilizada em substratos de mudas de várias espécies perenes (Martins Filho et al., 2007; Silva et at., 2009; Garcia et al., 2012; Araújo \& Paiva Sobrinho, 2011; Wanderley et al., 2012; Luz et al., 2013; Cavalcante et al., 2016; Pimentel et al., 2016; Pinheiro et al., 2018; Guse et al. 2021). Santos (2008) ressalta que na formação de mudas de pupunheira o melhor substrato deve ser aquele onde a muda apresente, no mínimo, quatro folhas, menor incidência pragas e doenças e alta taxa de sobrevivência. No presente estudo as mudas produzidas em substrato constituído por terriço + esterco bovino apresentaram, aos doze meses, mais de seis folhas, 19,65 mm de diâmetro do coleto, $100 \%$ de mudas vivas e sem ocorrência de pragas e doenças. Com base nessas informações pode-se considerar que o substrato contendo terriço acrescido de esterco bovino seja o mais indicado para a produção de mudas aptas para o plantio da espécie em foco.

\section{Conclusão}

O substrato orgânico constituído por terriço mais esterco bovino curtido, na proporção de 3:1 é o mais eficiente no desenvolvimento de mudas de bacabi (Oenocarpus mapora). As mudas produzidas com o substrato terriço mais esterco bovino estão prontas para o plantio aos nove meses, quando apresentam acima de cinco folhas e as melhores características vegetativas. O substrato orgânico terriço mais esterco bovino deve ser recomendado na produção de mudas dessa palmeira propagadas por sementes e em sacos de polietileno.

Novos estudos envolvendo diferentes proporções de esterco bovino curtido no substrato devem ser realizados.

\section{Referências}

Alves, T. N., Carvalho, E. L., Guedes, P. T. P., Nordi, N. T., Aires, E. S., Oliveira, M. M. V., Ono, E. O., \& Rodrigues, J. D. (2021). Produção de mudas de manjericão (Ocimum basilicum L.) sob efeito de diferentes substratos. Research, Society and Development, 10(2), e58210212867, http://dx.doi.org/10.33448/rsd-v10i2.12867.

Araújo, A. P., \& Paiva Sobrinho, S. de. (2011). Germinação e produção de mudas de tamboril (Enterolobium contortisiliquum) (VELL.). Revista Árvore, 3, 581-588. https://doi.org/10.1590/S0100-67622011000400001.

Araújo, J. B., Silva-Matos, R. R. S. da., Amorim, D. J., Morais, V. P., Araujo, G. B., Santos, G. M. da S., \& Cordeiro, K. V. (2020). Substrato a base de bagana de carnaúba na propagação vegetativa de Ocimum basilicum. Research, Society and Development, 9(9), e761997879, http://dx.doi.org/10.33448/rsdv9i9.7879.

Barros, C. M. B., Vanolli, B. da S., Vicensi, M., Ávila, F. W. do., Botelho, R. V., \& Muller, M. M. L. (2020). Substratos orgânicos e pulverização com biofertilizante na produção de mudas de mamoeiro. Research, Society and Development, 9(10), e6359109129, 20. http://dx.doi.org/10.33448/rsd-v9i10.9129.

Bellote, A. F. J., \& Silva, H. D. da. (2000). Técnicas de amostragem e avaliações nutricionais em plantios de Eucalyptus spp. In: Gonçalves, J. L. de M. \& BenedettI, V. Nutrição e fertilização florestal,105-133.

Brahm, R. Ü., Medeiros, C. A. B., Cardoso, J. H., \& Reisser Júnior, C. (2013). Avaliação do efeito de diferentes substratos sobre o desenvolvimento de Euterpe edulis Mart. e Rystonea regia Kunth. Revista Brasileira de Agroecologia, 8, 148-160. http://www.abaagroecologia.org.br/revistas/index.php/rbagroecologia/article/view/10033/8903.

Caldeira, M.V.W., Rosa, G.N. da., Fenilli, T. A. B., \& Harbs, R. M. P. (2008). Composto orgânico na produção de mudas de aroeira-vermelha. Scientia Agraria, Curutiba, 9, 27-33. http://dx.doi.org/10.5380/rsa.v9i1.9898.

Cavalcante, A. C. P., Cavalcante, A. G., da Silva, M. J. R., \& Costa Araújo, R. da. (2016). Produção de mudas de gliricídia com diferentes substratos orgânicos. Agrarian, 9 (33), 233-240. https://ojs.ufgd.edu.br/index.php/agrarian/article/view/3929/0.

Clement, C. R. (2001). Melhoramento de espécies nativas. In: Nass, L.L.; Valois, A.C.C.; Melo, I. S. de; Inglis, M. C. V. Recursos genéticos e melhoramento de plantas, 423-441. https://repositorio.inpa.gov.br/handle/1/33942. 
Comissão Estadual de Sementes e Mudas do Pará - CESM (Belém, Pa). 1997. Normas técnicas e padrões para a produção de mudas fiscalizadas no Estado do Pará: Açaizeiro, 40.

Cordeiro, K. V., Pereira, R. Y. F., Cardoso, J. P. S., Sousa, M. de O., Pontes, S. F., Oliveira, P. S. T. de, Marques, G. M., Costa, S. M. D de M., Oliveira, M. M. T. de., \& Silva-Matos, R. R. S. da. (2020). Eficiência do uso de substratos alternativos na produção de mudas de mamoeiro. Research, Society and Development, 9(9), e715997795, http://dx.doi.org/10.33448/rsd-v9i9.7795.

Cruz, C. D. (2001). Programa GENES - Versão Windows. Editora UFV. Viçosa, MG, 642. http://www.ufv.br/dbg/genes/genes.htm.

Fior, C. S., Pezzi, A., \& Schwarz, S. F. (2014). Desenvolvimento inicial de mudas de Butia odorata (Barb. Rodr.) Noblick cultivadas em recipientes. Revista Ceres, 61, 706-714. https://doi.org/10.1590/0034-737X201461050014.

Franco, C. F., Prado, R. de M., Brachirolli, L. F., \& Rozane, D. E. (2007). Curva de crescimento e marcha de absorção de macronutrientes em mudas de goiabeira. Revista Brasileira de Ciência do Solo, 31, 1429-1437. https://doi.org/10.1590/S0100-06832007000600020.

Garcia, V. A., Modolo, V. A., Lagôa, A. M. M. A., Tucci, M. L. S. A., Erismann, N. de M., \& Rodrigues, D. S. (2012). Crescimento de mudas de pupunheira (Bactris gasipaes Kunth) utilizando resíduo de areia como componente dos substratos. Revista Ciência Florestal, 22, 445-455. https://doi.org/10.5902/198050986613.

Gomes, J. M., \& Paiva, H. N. (2006). Viveiros florestais (propagação sexuada). Editora UFV.

Guse, L. G., Leão, A. C. D., Parra-Serrano, L. J. Furtado, M. B., \& Farias, M. F de. (2021). Produção de mudas de teca sob diferentes substratos orgânicos. Research, Society and Development, 10(5), e0910514611, http://dx.doi.org/10.33448/rsd-v10i5.14611.

Instituto Nacional de Metereologia (2019). Banco de dados meteorológico do INMET, Belém. https://bdmep.inmet.gov.br/. Acesso em: 20 de junho de 2021. Kratz, D. (2011). Substratos renováveis para produção de mudas de Eucalyptus benthamii maiden et cambage e Mimosa scabrella benth. Dissertação (Mestrado em Engenharia Florestal) - Universidade Federal do Paraná, Curitiba, Paraná. Brasil. https://hdl.handle.net/1884/25859.

Luz, P. B. da., Foléis, G. R. S., \& Marostega, T.N. (2013). Desenvolvimento de mudas de palmeira juçara em diferentes substratos e recipientes. Revista de Biologia e Ciência da Terra, 13, 199-205. http://joaootavio.com.br/bioterra/workspace/uploads/artigos/676-2867-1-pb-53df90d734add.pdf.

Luz,P. B. da, Paiva, P. D. de O., Tavares, A. R., Kanashiro, S., \& Aguiar, F. F. A. (2007). Efeito de diferentes substratos e adubação fosfatada no crescimento de mudas de Rhaphis excelsa (Thunb.) A. Henry ex. Rehder (Palmeira-ráfia). Revista Brasileira de Horticultura Ornamental, 31, 37-42. http://dx.doi.org/10.14295/rbho.v17i1.715.

Marques, L. O. D., Mello-Farias, P., de Lima, A. Y. B., Malgarim, M. B., \& Santos, R. F. dos. (2017). Desempenho de diferentes substratos e influência do frio na germinação de sementes de araçá amarelo. Revista da Jornada da Pós Graduação e Pesquisa, 14(1), 1169-1180. http://revista.urcamp.tche.br/index.php/rcjpgp/article/view/871/567.

Martins Filho, S., Ferreira, A., Andrade, B. S de, Rangel, R. M., \& Silva, M. F da. (2007). Diferentes substratos afetando o desenvolvimento de mudas de palmeiras. Revista CERES, 54, 80-86. https://www.redalyc.org/pdf/3052/305226663013.pdf.

Martins, R. F. (2011). Diferentes ambientes protegidos e substratos para a formação de mudas de bocaiúva, a partir de sementes pré-germinadas. Dissertação (Mestrado em Agronomia) - Universidade Estadual de Mato Grosso do Sul.

Menezes Júnior, F. O. G. \& Fernandes, H. S. (1999). Efeitos de substratos formulados com esterco de curral e substratos comerciais na produção de mudas de alface. Revista Científica Rural, 4, 15-23. http://www.bdpa.cnptia.embrapa.br/busca?b=ad\&id=766898\&biblioteca=va zio\&busca=autoria:\%22MENEZES\%20J\%C3\%9ANIOR,\%20F.\%20O.\%20G.\%22\&qFacets=autoria:\%22MENEZES\%20J\%C3\%9ANIOR,\%20F.\%20O.\%20 G. $\% 22 \&$ sort $=\&$ paginacao=t\&paginaAtual $=1$.

Müller, C. H., Júnior, J.F., Carvalho, J. E. U. de, Teixeira, L. B., \& Dutra, S. (2004). Avaliação da influência da cama de frango na composição de substrato para a formação de mudas de açaizeiro. (Comunicado Técnico, 89), Belém: Embrapa-CPATU. http://www.infoteca.cnptia.embrapa.br/infot eca/handle/doc/407129.

Nicolau Sobrinho, W. (2007) Adubação orgânica e mineral na composição química e produção do milheto (Pennisetum glaucum) no semi-árido. Dissertação (Mestrado em Zootecnia) - Universidade Federal de Campina Grande, Patos, Paraíba, Brasil. http://dspace.sti.ufcg.edu.br:8080/jspui/handle/riufcg/3348.

Oliveira, M. do S. P. de., \& Oliveira, N. P. de. (2015). Bacaba. In: Lopes, R., Oliveira, M do S. P de, Cavallari, M. M., Barbieri, R. L. \& Conceição, L. D. H. C. S da. Palmeiras Nativas do Brasil. Brasília, DF : Embrapa. Cap. 4, 117-154.

Oliveira, M. do S. P. de., \& Moura, E. F. (2010). Repetibilidade e número mínimo de medições para caracteres de cachos de bacabi (Oenocarpus mapora). Revista Brasileira de Fruticultura, 32. http://ainfo.cnptia.embrapa.br/digital/bitstream/item/29611/1/RepetibilidadeNumero.pdf.

Oliveira, P. S. T. de, Silva, F. L. de S., Cordeiro, K. V., Sousa, G. dos S., Nunes, R. L. S., Pereira, R. Y. F., Albano-Machado, F. G., Oliveira, M. M.T de \& Silva-Matos, R. R. S. da. (2020). Eficácia de substratos e substância húmica na produção de mudas de Spondia purpurea L. por estaquia. Research, Society and Development, 9 (8), e60985006, http://dx.doi.org/10.33448/rsd-v9i8.5006.

Pereira, P. C. (2005). Avaliação da qualidade de mudas de tamarindeiro produzidas em viveiro. Dissertação (Mestrado em Agronomia) - Universidade Federal de Uberlândia, 69.

Pimentel, L. D., Bruckner, C. H., Manfio, C. E., Motoike, S. Y., \& Martinez, H. E. P. (2016). Substrate, lime, phosphorus and topdress fertilization in macaw palm seedling production. Revista Árvore, Viçosa-MG, 40 (2), p.235-244, http://dx.doi.org/10.1590/0100-67622016000200006.

Pinheiro, J. I., de Sousa Oliveira, L., de Sousa, A. M., Garcia, K. G. V., \& Lima, L. A. (2018). Mudas de Mimosa caesalpiniaefolia Benth (Leguminosae: Mimosoideae) cultivadas em substratos orgânicos. Revista Verde de Agroecologia e Desenvolvimento Sustentável, 13(2), 265-269. http://dx.doi.org/10.18378/rvads.v13i2.5632. 
Research, Society and Development, v. 10, n. 8, e12210817086, 2021

(CC BY 4.0) | ISSN 2525-3409 | DOI: http://dx.doi.org/10.33448/rsd-v10i8.17086

Russomano, O. M. R., Kruppa, P. C., \& Coutinho, L. N. (2007). Doenças fúngicas em palmeiras ornamentais. Biológico, 69, 9-15. http://www.biologico.sp.gov.br/uploads/docs/bio/v69_1/russomano.pdf.

Santos, A. C. V dos. (2008). Produção de mudas florestais. Niterói, RJ. Programa Rio Rural (Manual Técnico, 6), 20. http://www.pesagro.rj.gov.br/downloads/riorural/06\%20Producao\%20de\%20mudas\%20florestais.pdf.

Silva, E. A. da., Maruyama, W. I., Oliveira, A. C. de., \& Bardiviesso, D. M. (2009). Efeito de diferentes substratos na produção de mudas de mangabeira (Hancornia speciosa). Revista Brasileira de Fruticultura, 31, 925-929. https://doi.org/10.1590/S0100-29452009000300043.

Taiz, L., Zeiger, E., Moller, I. A., \& Murphy, A. (2017). Fisiologia e desenvolvimento vegetal. (6a ed.), Artmed.

Tavares Júnior, A. (2004). Volume e granulometria de substrato na formação de mudas de café. Dissertação (Mestrado em Fitotecnia) - Escola Superior de Agricultura “Luiz de Queiroz”, Piracicaba - São Paulo, Brasil. 10.11606/D.11.2004.tde-22092004-145858.

Valois, A. C. C. (2014). Recursos genéticos de palmeiras. http://www.procitropicos.org.br/userfiles/file/recursos\%20gen\%c3\%89ticos\%2 0de\%20palmeiras.doc. Acesso em: 01.mar.2014.

Wanderley, C. da S., Faria, R. T. de., \& Ventura, M. U. (2012). Adubação química, adubação orgânica e extrato pirolenhoso no desenvolvimento de mudas de palmeiras fênix (Phoenix roebelenii). Semina: Ciências Agrárias, 33, 2233-2240. http://dx.doi.org/10.5433/1679-0359.2012v33n6p2233. 